\title{
Relationship between Fibroblast Growth Factor-23 and Mineral Metabolism in Chronic Kidney Disease
}

\author{
Kosaku Nitta \\ Department of Medicine, Kidney Center, Tokyo Women's Medical University, 8-1 Kawada-cho, Shinjuku-ku, Tokyo 162-8666, Japan \\ Correspondence should be addressed to Kosaku Nitta, nitta@kc.twmu.ac.jp \\ Received 27 August 2010; Accepted 28 October 2010 \\ Academic Editor: R. Khanna \\ Copyright () 2010 Kosaku Nitta. This is an open access article distributed under the Creative Commons Attribution License, which \\ permits unrestricted use, distribution, and reproduction in any medium, provided the original work is properly cited. \\ Fibroblast growth factor- (FGF-)23 is a recently discovered regulator of calcium-phosphate metabolism. FGF-23 appears to \\ decrease in synthesis and accelerated degradation of $1,25(\mathrm{OH})_{2} \mathrm{D}$. Together with its cofactor Klotho, FGF-23 maintains serum \\ phosphate levels within the normal range by increasing renal phosphate excretion. In chronic kidney disease (CKD), FGF-23 levels \\ rise in parallel with the decline in renal function long before a significant increase in serum phosphate concentration occurs. \\ Both Klotho and FGF-23, linked by a receptor mechanism, affect vitamin D synthesis and parathyroid hormone (PTH) secretion. \\ Previous studies have shown a close association between reduced FGF-23 or Klotho activities and vascular calcification. The \\ possible association of FGF-23 and left ventricular hypertrophy or vascular dysfunction has been proposed. Finally, prospective \\ studies have shown that high serum FGF-23 concentrations predict more rapid disease progression in CKD patients who were \\ not on dialysis and increased mortality in patients on maintenance hemodialysis. FGF-23 may therefore prove to be an important \\ therapeutic target for the management of CKD.
}

\section{Introduction}

Fibroblast growth factor- (FGF-) 23 is recently discovered and is involved in the control of phosphate $(\mathrm{P})$ and calcium (Ca) metabolism [1]. FGF-23 is a 251-amino acid protein (molecular weight; $26 \mathrm{kDa}$ ) that is synthesized and secreted by bone cells, mainly osteoblasts [2]. It is composed of an amino-terminal signal peptide (residues 1-24), an "FGFlike sequence" (residues 25-180), and a carboxyl-terminal extended sequence (residues 181-251), which is unique among members of the FGF family [3]. Since FGF-23 has low affinity for heparin, it can be distributed throughout the body in the blood and mediates its systemic function [4].

The biological activity and physiological role of FGF23 in $\mathrm{P}$ and vitamin $\mathrm{D}$ metabolism in vivo have recently been clarified. Several animal models with excess FGF23 activity as a result of in vivo forced overexpression exhibit hypophosphatemia and increased $\mathrm{P}$ excretion of 1,25-dihydroxyvitamin $\mathrm{D}\left[1,25(\mathrm{OH})_{2} \mathrm{D}\right]$ [5-8], and Fgf23 knockout $(\mathrm{KO})$ mice are characterized by increased renal $\mathrm{P}$ reabsorption and an elevated serum $1,25(\mathrm{OH})_{2} \mathrm{D}$ concentration $[9,10]$. FGF-23 appears to impair the synthesis and accelerate the degradation of $1,25(\mathrm{OH})_{2} \mathrm{D}$, because expression of renal 25 -hydroxyvitamin D- $1 \alpha$-hydroxylase mRNA changes within $1 \mathrm{~h}$ after injecting mice with recombinant FGF-23 [11]. The increased degradation of $1,25(\mathrm{OH})_{2} \mathrm{D}$ by 24-hydroxylase may be associated. Recombinant FGF-23 also has a phosphaturic effect, which is attributable to reduced renal $\mathrm{P}$ reabsorption. FGF-23 down-regulates the expression of both type IIa and type IIc sodium-P cotransporters on the apical surface of renal proximal tubular epithelial cells in vivo $[11,12]$.

\section{Measurement of Serum FGF-23 Levels}

The half-life of intact FGF-23 in the circulation of healthy individuals has been estimated to be $58 \mathrm{~min}$ [13]. Two assays for measurement of human FGF-23 are commercially available. One is a sandwich enzyme-linked immunosorbent assay for measurement of full-length FGF-23 that uses different monoclonal antibodies to detect the simultaneous presence of both the N-terminal [14] and C-terminal [15] portions of FGF-23. The other assay is a C-terminal assay 
that recognizes both full-length and processed (presumably inactive) C-terminal fragments of FGF-23. The intraassay variability of the C-terminal FGF-23 assay is $5 \%$ at $52.7 \mathrm{RU} / \mathrm{ml}$ and $7.2 \%$ at $140.0 \mathrm{RU} / \mathrm{ml}$, whereas interassay variability is $5 \%$ at $50.9 \mathrm{RU} / \mathrm{ml}$ and $7.3 \%$ at $153.0 \mathrm{RU} / \mathrm{ml}$. The lower limit of detection is $3.0 \mathrm{RU} / \mathrm{ml}$. The intra-assay variability of the intact FGF-23 assay is $4.4 \%$ at $14.6 \mathrm{pg} / \mathrm{ml}$ and $2.6 \%$ at $148.0 \mathrm{pg} / \mathrm{ml}$, and its interassay variability is $6.1 \%$ at $15.6 \mathrm{pg} / \mathrm{ml}$ and $6.5 \%$ at $166.0 \mathrm{pg} / \mathrm{ml}$. The lower limit of detection is $1.0 \mathrm{pg} / \mathrm{ml}$ (according to the manufacturer's specifications).

\section{Interaction between FGF-23 and Klotho}

Klotho is a $130-\mathrm{kDa}$ transmembrane $\beta$-glucuronidase that catalyzes the hydrolysis of steroid $\beta$-glucuronides and was discovered by Kuro-o et al. in 1997 [16]. The Klotho gene is expressed in a limited number of tissues, mainly the kidneys, and mutations cause multiple aging-related disorders in nearly all organs and tissues [17]. Because FGF-23-KO mice exhibit phenotypes similar to those of Klotho-KO mice $[18,19]$, a common signaling pathway has been postulated. Indeed, FGF-23 exerts its biological effects through activation of FGF receptors (FGF-Rs) in a Klothodependent manner, because a Klotho/FGF-R complex binds to FGF-23 with higher affinity than FGF-R or Klotho alone [20]. FGF-23 has rather low affinity for its widely represented receptors and the presence of circulating Klotho is essential to facilitate the binding of FGF-23 to its receptors [21]. Thus, activation of FGF-23 receptors requires not only presence of the circulating FGF-23 as their ligand, but the presence of Klotho as a specific promoter whose affinity dictates the selectivity on its targets.

Klotho is mainly expressed in the kidneys, whereas FGF23 comes from bone cells, and this functional bone-kidney axis is of physiological and pathological relevance. Based on available knowledge, this axis seems to exert a prevailing regulation of $\mathrm{Ca}$ balance with Klotho and to exert a more specific and direct effect on P homeostasis through FGF-23. Both Klotho and FGF-23, linked by the receptor mechanism described above, affect vitamin D synthesis and parathyroid hormone (PTH) secretion, and both are expressed in the parathyroid glands, suggesting that FGF-23 might regulate PTH secretion. In support of this possibility, data obtained in vitro suggest that FGF-23 decreases PTH mRNA transcription and protein secretion in a dose-dependent manner [22]. Conversely, PTH may stimulate FGF-23 secretion by osteoblasts, because the FGF-23 levels of rodents with primary hyperparathyroidism (HPT) are increased, which may be reduced by parathyroidectomy [23].

\section{Role of FGF-23 in Chronic Kidney Disease (CKD)}

Patients with stages 3-5 CKD and dialysis patients often develop hyperphosphatemia due to impaired renal $\mathrm{P}$ excretion. Decreased $1,25(\mathrm{OH})_{2} \mathrm{D}$ production interferes with this process. The decrease in vitamin $\mathrm{D}$ activation induces

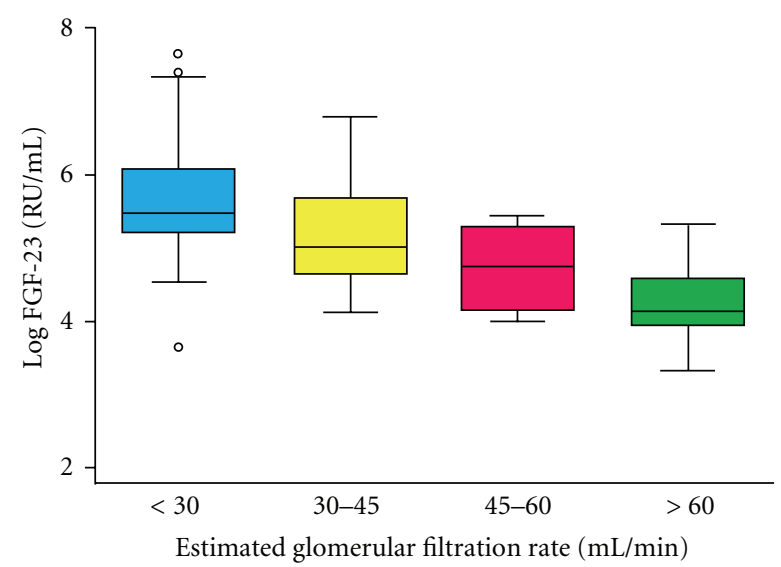

Figure 1: Serum fibroblast growth factor (FGF)-23 levels are negatively associated with estimated glomerular filtration rates. Cited from the J Am Soc Nephrol 2005; 16: 2205-15 by Gutiérrez et al. [24].

hypocalcemia and a subsequent increase in PTH secretion to maintain serum Ca levels normal but induces a high level of bone turnover and hyperphosphatemia [25].

It has been reported that serum FGF-23 levels increased as renal function declines [26, 27]; circulating FGF-23 levels of CKD patients gradually increase with declining renal function (Figure 1) [24]. It has been therefore hypothesized that the increased FGF-23 levels in CKD are primarily the result of decreased renal clearance [28]. By contrast, no association between FGF-23 levels and glomerular filtration rate has been found in the earlier stages of CKD, when patients are normophosphatemic [28]. The hyperphosphatemia associated with CKD most likely triggers FGF-23 production, which promotes renal phosphate excretion, reflected by the severely elevated FGF-23 levels in CKD subjects. In studies of healthy subjects exposed to an increased or decreased P load, conflicting results regarding a correlation between FGF23 and serum $P$ levels have been shown.

The cause of the increased FGF-23 levels in CKD patients is still under investigation. Instead of decreased renal clearance, there may be end-organ resistance to the phosphaturic action of FGF-23 because of a deficiency of the required Klotho cofactor. Koh et al. reported significantly reduced Klotho mRNA expression in kidney biopsy specimens of CKD patients [29]. The higher FGF-23 levels in CKD patients may reflect a physiological compensation that stabilizes serum $\mathrm{P}$ levels as the number of intact nephrons declines. FGF-23 increases urinary $\mathrm{P}$ excretion and decreases gastrointestinal $\mathrm{P}$ absorption both directly and indirectly by inhibiting $1 \alpha$-hydroxylase and reducing circulating $1,25(\mathrm{OH})_{2} \mathrm{D}$ levels [30].

Since FGF23 has a profound effect on down-regulating renal expression of the $1 \alpha$-hydroxylase, excess FGF23 in vivo may signal via parathyroid cells an increase in $\mathrm{PTH}$ production, as a part of a counter-regulatory feedback loop to protect the decrease in vitamin D and Ca levels. There are in vivo animal models of FGF-23 overexpression, and all of them are characterized by parathyroid hyperplasia and 


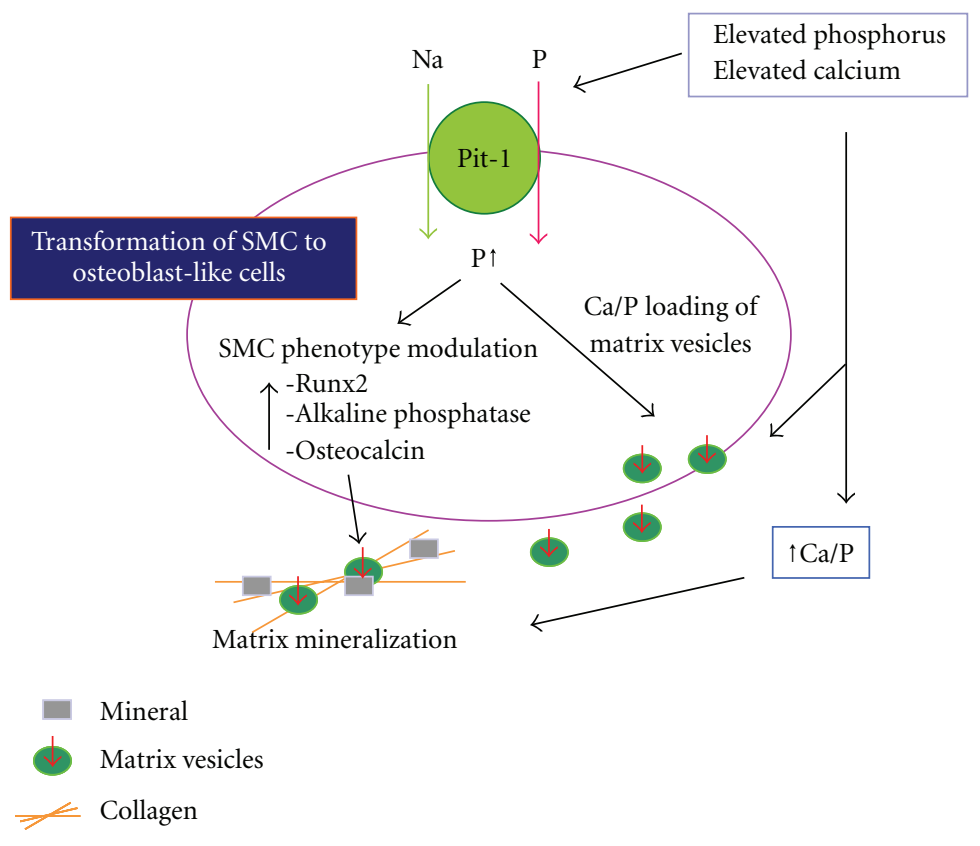

Figure 2: Proposed model for the effects of elevated Ca and P on vascular smooth muscle cell (SMC) matrix mineralization. Cited from the J Am Soc Nephrol 2004; 15: 2959-164 by Giachelli [31].

increased PTH levels [32]. A more likely scenario is that the increase in PTH levels and parathyroid hyperplasia observed in these animals is mediated by the Ca-sensing receptor, again protecting systemic Ca levels, because the suppressed $1,25(\mathrm{OH})_{2} \mathrm{D}$ levels would lead to persistent hypocalcemia. Indeed, mice expressing high systemic levels of FGF-23 (R176Q) exhibit hypocalcemia and subsequent development of secondary HPT, even though their elevated PTH levels are likely to aggravate the prevailing hypophosphatemia [33].

\section{FGF-23 and Vascular Calcification}

CKD patients have dramatically higher cardiovascular morbidity and mortality rates than the general population [34]. In the last 10 years, several studies have pointed to vascular calcification as a major cause of cardiovascular disease in the dialysis population [35-39]. CKD patients develop extensive medial calcification, which causes increased arterial stiffness and high morbidity and mortality due to cardiovascular events [40]. Vascular calcification alters the pulsatile dynamics and thereby contributes to an increase in left ventricular load, and it is the most important contributor to the development of left ventricular hypertrophy in patients undergoing hemodialysis [41]. A variety of risk factors are associated with vascular calcification in dialysis patients (dialysis vintage, uremic toxins, history of diabetes, inflammation), but abnormalities in bone mineral metabolism may play a critical role [42]. In fact, elevated serum $\mathrm{P}$ and PTH levels contribute to vascular calcification, although their roles are incompletely understood. Elevated serum P levels may worsen cardiovascular events in the uremic population by progressively increasing calcium deposition in the coronary arteries and heart valves [43].

Jono et al. showed that elevated P levels $(>2.4 \mathrm{mM})$ induce smooth muscle cell (SMC) calcification in vitro [44]. $\mathrm{P}$ transport into cells from the extracellular compartment is primarily mediated by membrane transporters called sodium-dependent $\mathrm{P}$ cotransporters, and a type III sodiumdependent $\mathrm{P}$ cotransporter, Pit-1, has been found to be associated with SMC calcification [45]. Likewise, increasing the Ca levels in culture media to levels that are considered hypercalcemic ( $>2.6 \mathrm{mM}$ ) leads to increased mineralization and phenotypic transition of SMCs [46]. Elevated Cainduced mineralization is also dependent on Pit-1. Figure 2 depicts the mechanism of vascular calcification as a result of transformation of SMC to osteoblast-like cells [31].

Both human and animal studies have shown a close association between reduced FGF-23 or Klotho activities and vascular calcification. Extensive vascular calcification is observed in Fgf23-KO mice by 6 weeks of age [47], interestingly, expression of the sodium-P cotransporter NaPi2a by their proximal tubular epithelial cells is upregulated. Moreover, the bone mineral density (BMD) of Fgf23$\mathrm{KO}$ mice is strikingly reduced. Human studies have also shown an association between reduced BMD and vascular calcification [48], and low BMD has been suggested to independently predict coronary artery in women, with a higher odds ratio than traditional risk factors [49]. In view of the phenotypes of both Fgf23- and Kloth-KO mice, it seems likely that in vivo dysregulation of the FGF-23-Klotho axis can lead to vascular calcification, possibly by affecting mineral ion metabolism [50]. 

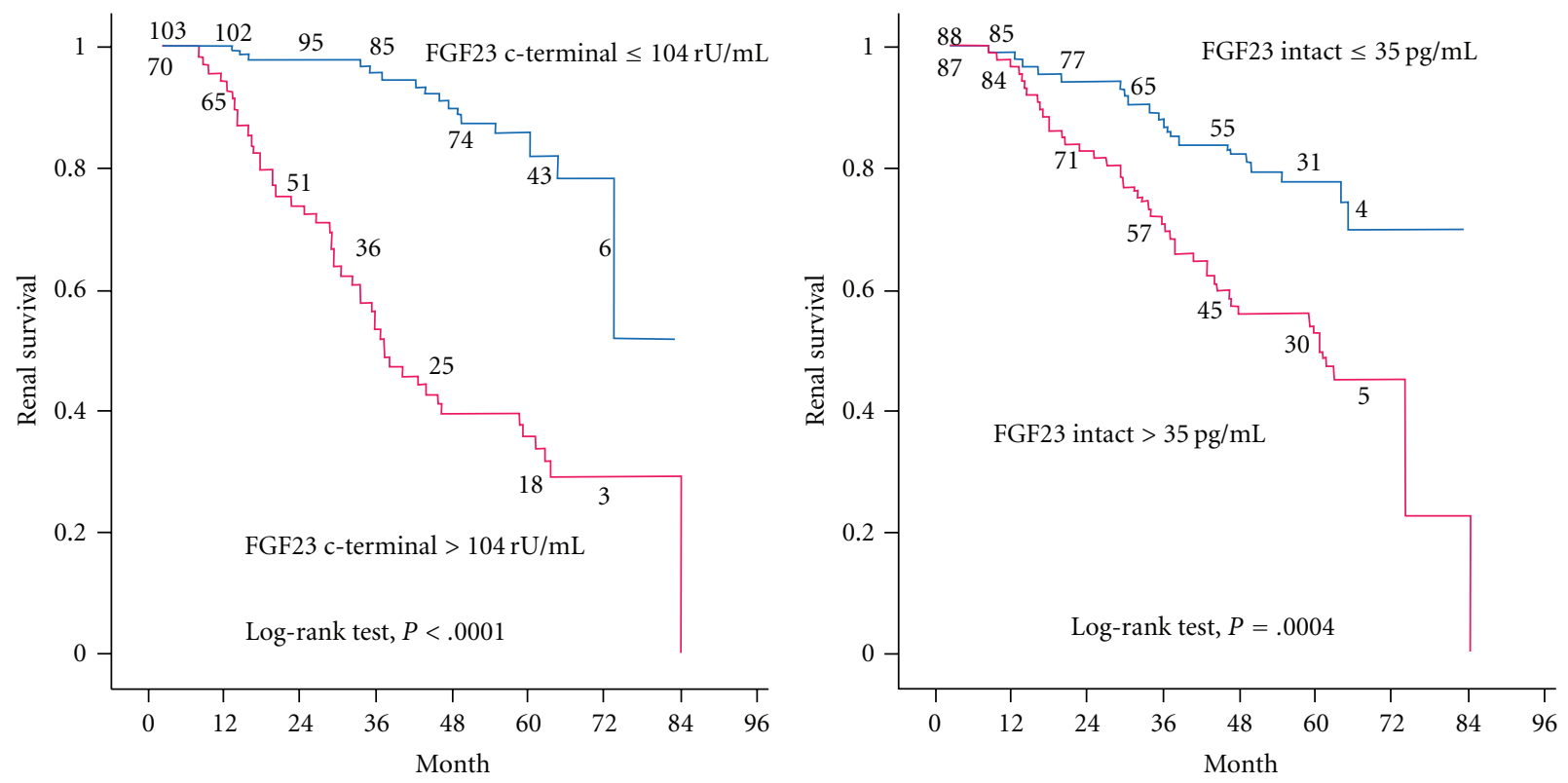

Figure 3: Association between serum FGF-23 levels and renal survival. Cited from the J Am Soc Nephrol 2007; 18: 2600-8 by Fliser et al. [27].

\section{FGF-23 As a Prognostic Factor in CKD Patients}

Interest in FGF-23 increased tremendously after the publication of two prospective cohort studies in which FGF-23 was identified as a risk factor for a poorer outcome in CKD patients. The ArMORR study revealed that high FGF-23 levels in patients starting hemodialysis were an independent predictor of 1-year mortality after adjustment for serum $\mathrm{P}$ levels [51], and in a multivariable adjusted model, subjects whose FGF-23 levels were in the highest quartile had nearly a sixfold increase in risk in mortality over the subjects in the lowest quartile. Thus, FGF-23 was a much stronger predictor of mortality than serum $\mathrm{P}$ levels. In the MMKD trial [27], 227 patients with nondiabetic stages 1-4 CKD were prospectively followed up for a median of 53 months to assess the progression of renal disease. Among the various parameters of Ca-P metabolism evaluated, FGF-23 levels were a significant independent predictor of CKD progression (Figure 3), which was defined as a doubling of the serum creatinine level and/or terminal renal failure. Again, the FGF23 levels were a better outcome predictor than the serum $\mathrm{P}$ levels, and in a Cox regression analysis the $\mathrm{P}$ levels lost their predictive value after adjusting for FGF-23.

Serum FGF-23 levels have been reported to be independently related to aortic calcification index in hemodialysis patients [52]. Jean et al. reported an association between serum FGF-23 levels and increased mortality in long hemodialysis patients [53]. Multivariate linear regressions have shown a correlation between phosphatemia and serum FGF-23 levels, confirming the association between higher serum FGF-23 levels with mortality and vascular calcification regardless of the serum $P$ levels. On the other hand, Inaba et al. found that plasma FGF-23 level of both male nondiabetic and diabetic hemodialysis patients is an independent factor negatively associated with peripheral vascular calcification in the hand artery, but not in aorta, even when adjusted for the Ca $\mathrm{x} P$ product [54]. Thus, serum FGF-23 levels may provide a reliable marker for Moenckeberg's medial calcification in male hemodialysis patients, independent of the regulatory effect of FGF-23 on P metabolism, followed by increased mortality in these patients [55].

\section{Conclusion and Future Prospects}

FGF-23 is a recently discovered regulator of $\mathrm{Ca}$ and $\mathrm{P}$ metabolism. Serum FGF-23 levels have been reported to increase in the very early stages of $\mathrm{CKD}$, and the increase may represent a long-term, delayed response to transient episodes of hyperphosphatemia occurring in the early stage of $\mathrm{CKD}$, possibly when the rapid response of $\mathrm{PTH}$ is becoming insufficient. Accordingly, both FGF-23 and PTH are involved in the adaptive response to ensuing secondary hyperparathyroidism, with the difference that PTH accentuates the calcitriol deficiency but FGF-23 does not.

In clinical trials, elevated FGF-23 levels have been found to be independently associated with more rapid progression of CKD, therapy-resistant secondary HPT [56], and increased cardiovascular mortality in dialysis patients. However, FGF-23 is not just an innocent bystander that reflects unfavorable derangements of $\mathrm{Ca}-\mathrm{P}$ metabolism (e.g., increased serum phosphate levels) in CKD, but a pathophysiologically relevant factor. Thus, FGF-23 is a promising candidate for a therapeutic target that might improve the fatal prognosis of CKD patients. Since any increase in serum $\mathrm{P}$ level seems to link between CKD and cardiovascular disease, clinical interest in FGF-23 seems to be appropriate. 
It has recently been reported that FGF-23 is independently associated with left ventricular hypertrophy in patients with CKD [57]. In addition, circulating FGF-23 has been associated with vascular dysfunction in the community [58]. Additional studies are required to determine possible direct effects on the left ventricle and vasculature. A recent study that evaluated serum FGF-23 levels in a cohort of patients starting dialysis found that its quartiles are progressively and independently associated with mortality. Moreover, FGF-23 may be a cause of $1,25(\mathrm{OH})_{2} \mathrm{D}$ insufficiency, and that could be a further link with increased mortality, in view of the role of vitamin $\mathrm{D}$ receptor activation that is claimed to exist in several disease conditions. Finally, the functional interplay between FGF-23 and Klotho may represent another link with mortality.

\section{References}

[1] T. Yamashita, M. Yoshioka, and N. Itoh, "Identification of a novel fibroblast growth factor, FGF-23, preferentially expressed in the ventrolateral thalamic nucleus of the brain," Biochemical and Biophysical Research Communications, vol. 277, no. 2, pp. 494-498, 2000.

[2] M. Riminucci, M. T. Collins, N. S. Fedarko et al., "FGF23 in fibrous dysplasia of bone and its relationship to renal phosphate wasting," Journal of Clinical Investigation, vol. 112, no. 5, pp. 683-692, 2003.

[3] T. Yamashita, "Structural and biochemical properties of fibroblast growth factor 23," Therapeutic Apheresis and Dialysis, vol. 9, no. 4, pp. 313-318, 2005.

[4] L. D. Quarles, "Endocrine functions of bone in mineral metabolism regulation," Journal of Clinical Investigation, vol. 118, no. 12, pp. 3820-3828, 2008.

[5] X.-Y. Bai, D. Miao, D. Goltzman, and A. C. Karaplis, "The autosomal dominant hypophosphatemic rickets R176Q mutation in fibroblast growth factor 23 resists proteolytic cleavage and enhances in vivo biological potency," Journal of Biological Chemistry, vol. 278, no. 11, pp. 9843-9849, 2003.

[6] T. Larson, R. Marsell, E. Schipani et al., "Transgenic mice expressing fibroblast growth factor 23 under the control of the $\alpha 1$ (I) collagen promoter exhibit growth retardation, osteomalacia, and disturbed phosphate homeostasis," Endocrinology, vol. 145, no. 7, pp. 3087-3094, 2004.

[7] T. Shimada, I. Urakawa, Y. Yamazaki et al., "FGF-23 transgenic mice demonstrate hypophosphatemic rickets with reduced expression of sodium phosphate cotransporter type IIa," Biochemical and Biophysical Research Communications, vol. 314, no. 2, pp. 409-414, 2004.

[8] X. Bai, D. Miao, J. Li, D. Goltzman, and A. C. Karaplis, "Transgenic mice overexpressing human fibroblast growth factor 23 (R176Q) delineate a putative role for parathyroid hormone in renal phosphate wasting disorders," Endocrinology, vol. 145, no. 11, pp. 5269-5279, 2004.

[9] D. Sitara, M. S. Razzaque, M. Hesse et al., "Homozygous ablation of fibroblast growth factor-23 results in hyperphosphatemia and impaired skeletogenesis, and reverses hypophosphatemia in Phex-deficient mice," Matrix Biology, vol. 23, no. 7, pp. 421-432, 2004.

[10] T. Shimada, M. Kakitani, Y. Yamazaki et al., "Targeted ablation of Fgf23 demonstrates an essential physiological role of FGF23 in phosphate and vitamin D metabolism," Journal of Clinical Investigation, vol. 113, no. 4, pp. 561-568, 2004.
[11] T. Shimada, H. Hasegawa, Y. Yamazaki et al., "FGF-23 is a potent regulator of vitamin D metabolism and phosphate homeostasis," Journal of Bone and Mineral Research, vol. 19, no. 3, pp. 429-435, 2004.

[12] H. Segawa, E. Kawakami, I. Kaneko et al., "Effect of hydrolysisresistant FGF23-R179Q on dietary phosphate regulation of the renal type-II Na/Pi transporter," Pflugers Archiv European Journal of Physiology, vol. 446, no. 5, pp. 585-592, 2003.

[13] A. Khosravi, C. M. Cutler, M. H. Kelly et al., "Determination of the elimination half-life of fibroblast growth factor-23," Journal of Clinical Endocrinology and Metabolism, vol. 92, pp. 2374-2377, 2007.

[14] Y. Yamazaki, R. Okazaki, M. Shibata et al., "Increased circulatory level of biologically active full-length FGF-23 in patients with hypophosphatemic rickets/osteomalacia," Journal of Clinical Endocrinology and Metabolism, vol. 87, no. 11, pp. 4957-4960, 2002.

[15] Y. Imanishi, M. Inaba, K. Nakatsuka et al., "FGF-23 in patients with end-stage renal disease on hemodialysis," Kidney International, vol. 65, no. 5, pp. 1943-1946, 2004.

[16] M. Kuro-o, Y. Matsumura, H. Aizawa et al., "Mutation of the mouse klotho gene leads to a syndrome resembling ageing," Nature, vol. 390, no. 6655, pp. 45-51, 1997.

[17] H. Tsujikawa, Y. Kurotaki, T. Fujimori, K. Fukuda, and Y.-I. Nabeshima, "Klotho, a gene related to a syndrome resembling human premature aging, functions in a negative regulatory circuit of vitamin D endocrine system," Molecular Endocrinology, vol. 17, no. 12, pp. 2393-2403, 2003.

[18] M. S. Razzaque, D. Sitara, T. Taguchi, R. St-Arnaud, and B. Lanske, "Premature aging-like phenotype in fibroblast growth factor 23 null mice is a vitamin D-mediated process," FASEB Journal, vol. 20, no. 6, pp. 720-722, 2006.

[19] T. Nakatani, B. Sarraj, M. Ohnishi et al., "In vivo genetic evidence for klotho-dependent, fibroblast growth factor 23 (Fgf23) -mediated regulation of systemic phosphate homeostasis," FASEB Journal, vol. 23, no. 2, pp. 433-441, 2009.

[20] H. Kurosu, Y. Ogawa, M. Miyoshi et al., "Regulation of fibroblast growth factor-23 signaling by Klotho," Journal of Biological Chemistry, vol. 281, no. 10, pp. 6120-6123, 2006.

[21] M. Mohammadi, S. K. Olsen, and O. A. Ibrahimi, "Structural basis for fibroblast growth factor receptor activation," Cytokine and Growth Factor Reviews, vol. 16, pp. 107-137, 2005.

[22] T. Krajisnik, P. Björklund, R. Marsell et al., "Fibroblast growth factor- 23 regulates parathyroid hormone and $1 \alpha$-hydroxylase expression in cultured bovine parathyroid cells," Journal of Endocrinology, vol. 195, no. 1, pp. 125-131, 2007.

[23] T. Kawata, Y. Imanishi, K. Kobayashi et al., "Parathyroid hormone regulates fibroblast growth factor- 23 in a mouse model of primary hyperparathyroidism," Journal of the American Society of Nephrology, vol. 18, no. 10, pp. 2683-2688, 2007.

[24] O. Gutiérrez, T. Isakova, E. Rhee et al., "Fibroblast growth factor-23 mitigates hyperphosphatemia but accentuates calcitriol deficiency in chronic kidney disease," Journal of the American Society of Nephrology, vol. 16, no. 7, pp. 2205-2215, 2005.

[25] M. Cozzolino, A. Galassi, M. Gallieni, and D. Brancaccio, "Pathogenesis and treatment of secondary hyperparathyroidism in dialysis patients: the role of paricalcitol," Current Vascular Pharmacology, vol. 6, no. 2, pp. 148-153, 2008.

[26] N. Nagano, S. Miyata, M. Abe et al., "Effect of manipulating serum phosphorus with phosphate binder on circulating PTH and FGF23 in renal failure rats," Kidney International, vol. 69, no. 3, pp. 531-537, 2006. 
[27] D. Fliser, B. Kollerits, U. Neyer et al., "Fibroblast Growth Factor 23 (FGF23) predicts progression of chronic kidney disease. The Mild to Moderate Kidney Disease (MMKD) study," Journal of the American Society of Nephrology, vol. 18, no. 9, pp. 2601-2608, 2007.

[28] T. Larsson, U. Nisbeth, Ö. Ljunggren, H. Jüppner, and K. B. Jonsson, "Circulating concentration of FGF-23 increases as renal function declines in patients with chronic kidney disease, but does not change in response to variation in phosphate intake in healthy volunteers," Kidney International, vol. 64, no. 6, pp. 2272-2279, 2003.

[29] N. Koh, T. Fujimori, S. Nishiguchi et al., "Severely reduced production of klotho in human chronic renal failure kidney," Biochemical and Biophysical Research Communications, vol. 280, no. 4, pp. 1015-1020, 2001.

[30] S. Seiler, G. H. Heine, and D. Fliser, "Clinical relevance of FGF23 in chronic kidney disease," Kidney International, no. 114, supplement, pp. S34-S42, 2009.

[31] C. M. Giachelli, "Vascular calcification mechanisms," Journal of the American Society of Nephrology, vol. 15, no. 12, pp. 29592964, 2004.

[32] V. Lavi-Moshayoff, J. Silver, and T. Naveh-Many, "Human PTH gene regulation in vivo using transgenic mice," American Journal of Physiology, vol. 297, no. 3, pp. F713-F719, 2009.

[33] M. S. Razzaque and B. Lanske, "The emerging role of the fibroblast growth factor-23-klotho axis in renal regulation of phosphate homeostasis," Journal of Endocrinology, vol. 194, no. 1, pp. 1-10, 2007.

[34] R. N. Foley, A. M. Murray, S. Li et al., "Chronic kidney disease and the risk for cardiovascular disease, renal replacement, and death in the United States medicare population, 1998 to 1999," Journal of the American Society of Nephrology, vol. 16, no. 2, pp. 489-495, 2005.

[35] J. Blacher, A. P. Guerin, B. Pannier, S. J. Marchais, and G. M. London, "Arterial calcification, arterial stiffness, and cardiovascular risk I end-stage renal disease," Hypertension, vol. 38, pp. 938-942, 2001.

[36] A. Y.-M. Wang, M. Wang, J. Woo et al., "Cardiac valve calcification as an important predictor for all-cause mortality and cardiovascular mortality in long-term peritoneal dialysis patients: a prospective study," Journal of the American Society of Nephrology, vol. 14, no. 1, pp. 159-168, 2003.

[37] S. Okuno, E. Ishimura, K. Kitatani et al., "Presence of abdominal aortic calcification is significantly associated with all-cause and cardiovascular mortality in maintenance hemodialysis patients," American Journal of Kidney Diseases, vol. 49, no. 3, pp. 417-425, 2007.

[38] M. K. Sigrist, M. W. Taal, P. Bungay, and C. W. McIntyre, "Progressive vascular calcification over 2 years is associated with arterial stiffening and increased mortality in patients with stages 4 and 5 chronic kidney disease," Clinical Journal of the American Society of Nephrology, vol. 2, no. 6, pp. 1241-1248, 2007.

[39] T. Ogawa, H. Ishida, M. Akamatsu et al., "Progression of aortic arch calcification and all-cause and cardiovascular mortality in chronic hemodialysis patients," International Urology and Nephrology, vol. 42, no. 1, pp. 187-194, 2010.

[40] G. M. London, "Cardiovascular calcifications in uremic patients: clinical impact on cardiovascular function," Journal of the American Society of Nephrology, vol. 14, supplement 4, pp. S305-S309, 2003.

[41] K. Nitta, T. Akiba, K. Uchida et al., "Left ventricular hypertrophy is associated with arterial stiffness and vascular calcification in hemodialysis patients," Hypertension Research, vol. 27, no. 1, pp. 47-52, 2004.

[42] M. Cozzolino, S. Mazzaferro, F. Pugliese, and D. Brancaccio, "Vascular calcification and uremia: what do we know?" American Journal of Nephrology, vol. 28, no. 2, pp. 339-346, 2008.

[43] A. Covic, P. Kothawala, S. Robbins et al., "Systematic review of the evidence underlying the association between mineral metabolism disturbances and risk of all-cause mortality, cardiovascular mortality and cardiovascular events in chronic kidney disease," Nephrology Dialysis Transplantation, vol. 24, no. 5, pp. 1506-1523, 2009.

[44] S. Jono, M. D. McKee, C. E. Murry et al., "Phosphate regulation of vascular smooth muscle cell calcification," Circulation Research, vol. 87, no. 7, pp. E10-E17, 2000.

[45] X. Li, H. Y. Yang, and C. M. Giachelli, "Role of the sodiumdependent phosphate cotransporter, Pit-1, in vascular smooth muscle cell calcification," Circulation Research, vol. 98, no. 7, pp. 905-912, 2006.

[46] H. Yang, G. Curinga, and C. M. Giachelli, "Elevated extracellular calcium levels induce smooth muscle cell matrix mineralization in vitro," Kidney International, vol. 66, no. 6, pp. 2293-2299, 2004.

[47] D. Sitara, M. S. Razzaque, R. St-Armaud et al., "Geetic ablation of vitamin D activation pathway reverses biochemical and skeletal anormalies in Fgf-23 null animals," American Journal of Pathology, vol. 169, pp. 2161-2170, 2006.

[48] A. Aoki, F. Kojima, K. Uchida, Y. Tanaka, and K. Nitta, "Associations between vascular calcification, arterial stiffness and bone mineral density in chronic hemodialysis patients," Geriatrics and Gerontology International, vol. 9, no. 3, pp. 246252, 2009.

[49] P. A. Narcovitz, H. H. Tran, B. A. Franklin et al., "Usefulness of bone mineral density to predict significant coronary artery disease," American Journal of Cardiology, vol. 96, pp. 10591063, 2005.

[50] B. Lanske and M. S. Razzaque, "Mineral metabolism and aging: the fibroblast growth factor 23 enigma," Current Opinion in Nephrology and Hypertension, vol. 16, no. 4, pp. 311-318, 2007.

[51] O. M. Gutiérrez, M. Mannstadt, T. Isakova et al., "Fibroblast growth factor 23 and mortality among patients undergoing hemodialysis," New England Journal of Medicine, vol. 359, no. 6, pp. 584-592, 2008.

[52] M. M. Nasrallah, A. R. El-Shehaby, M. M. Salem, N. A. Osman, E. El Sheikh, and U. A. Sharaf El Din, "Fibroblast growth factor-23 (FGF-23) is independently correlated to aortic calcification in haemodialysis patients," Nephrology Dialysis Transplantation, vol. 25, no. 8, pp. 2679-2685, 2010.

[53] G. Jean, J.-C. Terrat, T. Vanel et al., "High levels of serum fibroblast growth factor (FGF)-23 are associated with increased mortality in long haemodialysis patients," Nephrology Dialysis Transplantation, vol. 24, no. 9, pp. 2792-2796, 2009.

[54] M. Inaba, S. Okuno, Y. Imanishi et al., "Role of fibroblast growth factor-23 in peripheral vascular calcification in nondiabetic and diabetic hemodialysis patients," Osteoporosis International, vol. 17, no. 10, pp. 1506-1513, 2006.

[55] G. Jean, E. Bresson, J.-C. Terrat et al., "Peripheral vascular calcification in long-haemodialysis patients: associated factors and survival consequences," Nephrology Dialysis Transplantation, vol. 24, no. 3, pp. 948-955, 2009. 
[56] S. Nakanishi, J. J. Kazama, T. Nii-Kono et al., "Serum fibroblast growth factor-23 levels predict the future refractory hyperparathyroidism in dialysis patients," Kidney International, vol. 67, no. 3, pp. 1171-1178, 2005.

[57] O. M. Gutiérrez, J. L. Januzzi, T. Isakova et al., "Fibroblast growth factor 23 and left ventricular hypertrophy in chronic kidney disease," Circulation, vol. 119, no. 19, pp. 2545-2552, 2009.

[58] M. A. I. Mirza, A. Larsson, L. Lind, and T. E. Larsson, "Circulating fibroblast growth factor-23 is associated with vascular dysfunction in the community," Atherosclerosis, vol. 205, no. 2, pp. 385-390, 2009. 


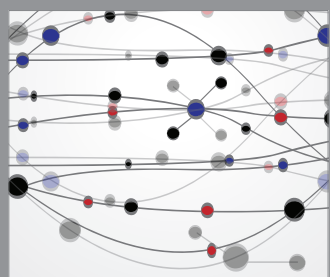

The Scientific World Journal
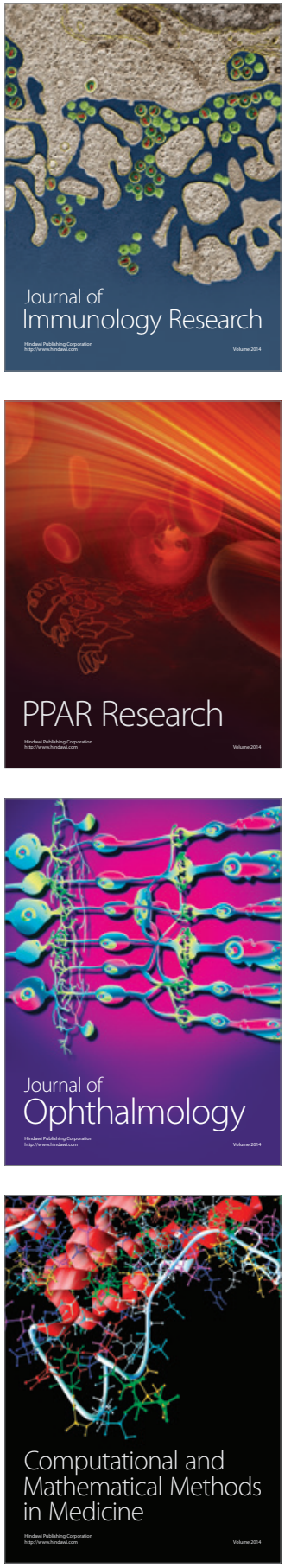

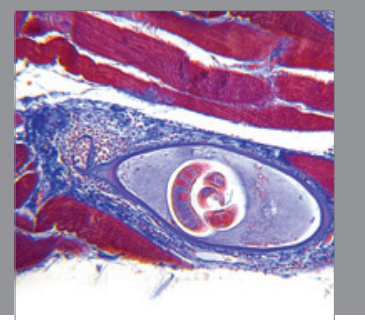

Gastroenterology

Research and Practice
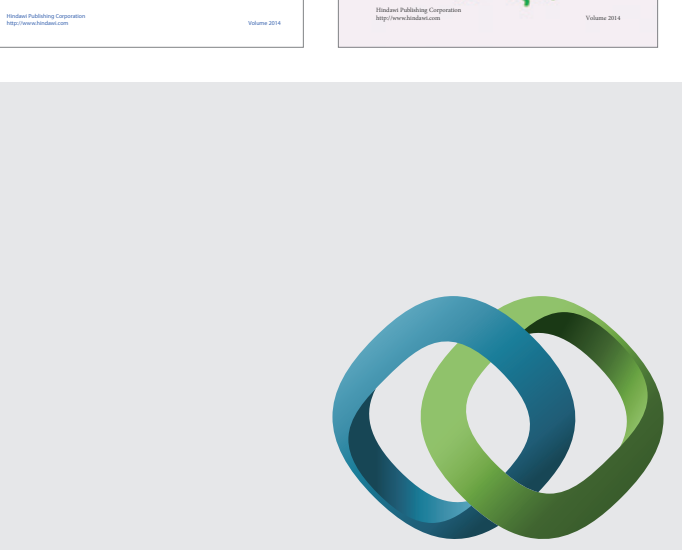

\section{Hindawi}

Submit your manuscripts at

http://www.hindawi.com
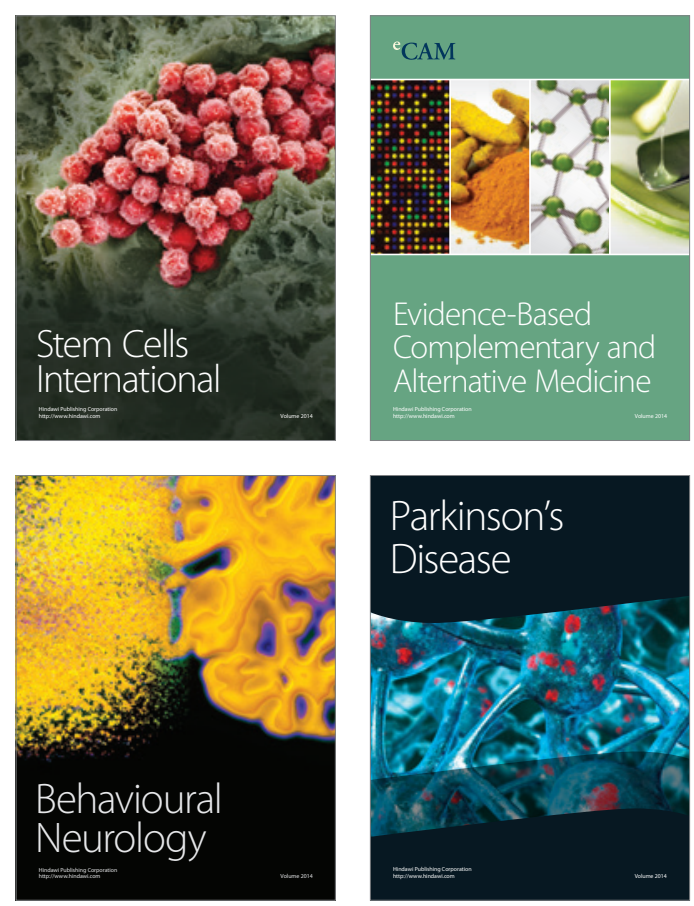

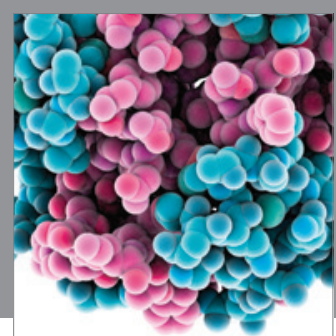

Journal of
Diabetes Research

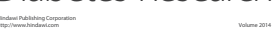

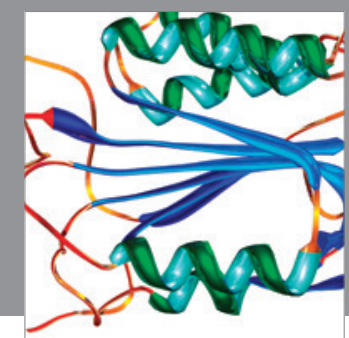

Disease Markers
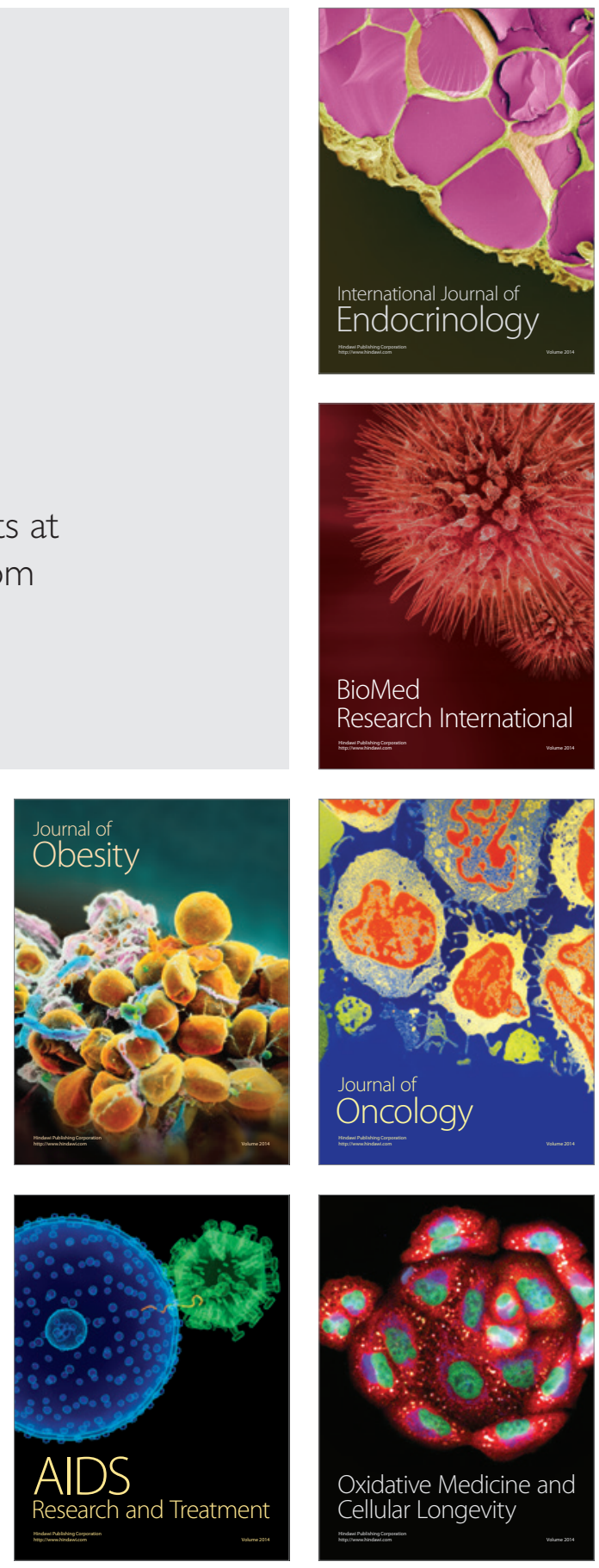